\title{
Ambient fabrication of perovskite solar cells through delay-deposition technique
}

\author{
Puteri Nor Aznie Fahsyar ${ }^{1,2}$ - Norasikin Ahmad Ludin ${ }^{1}$ ( ) Noor Fadhilah Ramli ${ }^{1}$ Mohamad Firdaus Mohamad Noh ${ }^{1}$. \\ Rozan Mohamad Yunus ${ }^{3} \cdot$ Suhaila Sepeai $^{1} \cdot$ Mohd Adib Ibrahim $^{1} \cdot$ Mohd Asri Teridi $^{1} \cdot$ Kamaruzzaman Sopian $^{1}$
}

Received: 27 September 2020 / Accepted: 3 June 2021 / Published online: 7 June 2021

(c) The Author(s) 2021

\begin{abstract}
The establishment of perovskite solar cells (PSCs) in terms of their power-conversion efficiency (PCE) over silicon-based solar cells is undeniable. The state-of-art of easy device fabrications of PSCs has enabled them to rapidly gain a place in third-generation photovoltaic technology. Numerous obstacles remain to be addressed in device efficiency and stability. Low performance owing to easily degraded surface and deterioration of perovskite film quality resulting from humidity are issues that often arise. This work explored a new approach to producing high-quality perovskite films prepared under high relative humidity $(\mathrm{RH}=40 \%-50 \%)$. In particular, the ubiquitous 4-tert-butylpyridine (tBp) was introduced into lead iodide $\left(\mathrm{PbI}_{2}\right)$ precursor as an additive, and the films were fabricated using a two-step deposition method followed by a delay-deposition technique of methylammonium iodide (MAI). High crystallinity and controlled nucleation of MAI were needed, and this approach revealed the significance of time control to ensure high-quality films with large grain size, high crystallography, wide coverage on substrate, and precise and evenly coupled MAI molecules to $\mathrm{PbI}_{2}$ films. Compared with the two-step method without time delay, a noticeable improvement in PCE from 3.2 to $8.3 \%$ was achieved for the sample prepared with $15 \mathrm{~s}$ time delay. This finding was primarily due to the significant enhancement in the open-circuit voltage, short-circuit current, and fill factor of the device. This strategy can effectively improve the morphology and crystallinity of perovskite films, as well as reduce the recombination of photogenerated carriers and increase of current density of devices, thereby achieving improved photovoltaic performance.
\end{abstract}

Keywords 4-tert-Butylpyridine $\cdot$ High relative humidity $\cdot$ Two-step $\cdot$ Delay deposition $\cdot$ Perovskite solar cells

\section{Introduction}

The development of perovskite solar cells (PSCs) based on hybrid organic-inorganic halide as absorber material yields remarkable properties, including low-temperature solution processability, high light absorption coefficient, tunability, and ambipolar carrier-diffusion properties [1-5]. Owing to these characteristics, the PSC fabrication methods used to achieve desired outcomes have been diversified. In

Norasikin Ahmad Ludin

sheekeen@ukm.edu.my

1 Solar Energy Research Institute, University Kebangsaan Malaysia, Selangor, Malaysia

2 School of Engineering, UOW Malaysia KDU, Selangor, Malaysia

3 Fuel Cell Institute, University Kebangsaan Malaysia, Selangor, Malaysia particular, the certified power-conversion efficiency (PCE) reached in the year $2020(25.2 \%)$ outperformed that of multicrystalline silicon solar cells (23.3\%) [6]. To date, solution processing is the most adopted approach for PSC fabrication because of the facile procedures, low-temperature requirement, can be produced in the laboratory, and low-cost fabrications [7-11].

Two methods that are frequently used by researchers across the region are one- and two-step (TS) deposition method. For the one-step method, lead iodide $\left(\mathrm{PbI}_{2}\right)$ and methylammonium iodide (MAI) solution are mixed to form perovskite films. Both organic and inorganic precursors are required to be dissolved before deposition onto the substrate. However, the capability of controlling the film properties including thickness, surface roughness, and uniformity of grain size are reduced owing to uncontrolled precipitation in one-step deposition, thereby leading to inconsistent photovoltaic performance $[12,13]$. Owing to these restraints, the 
TS method has been introduced to overcome the drawbacks of the one-step method. In the TS method, $\mathrm{PbI}_{2}$ solution in dimethylformamide (DMF) was spin coated onto $\mathrm{TiO}_{2}$ films followed by the dipping of MAI solution in 2-propanol to form high-quality perovskite films for PSCs [14]. Many studies have implemented the TS method to increase the PCE of PSCs [12, 15-17]. Apart from deposition, several strategies have been incorporated for controlling morphological properties, such as vacuum flash-assisted solution processes [18], moisture mechanism control [15, 16], and mixed precursors [19]. Despite all these brilliant innovative technologies, the performance of PSCs is relatively vulnerable to humidity, thereby restricting the fabrication process of such solar cells [20]. To address this issue, feasible methods of fabricating PSCs in ambient atmosphere are highly desirable to develop.

In achieving very dense and smooth perovskite morphology, the crucial part is to regulate the nucleation and crystallisation kinetics during film formation to obtain perovskite films with high efficiency and stability [21]. To control perovskite crystallisation, previous studies have developed various methods, such as solvent engineering [22], composition re-engineering [3], introducing additional additive, and others [7, 15, 23, 24]. Amongst these methods, the easiest and most effective way to achieve the specific target is by adding additives to the precursor perovskite solution [25]. Before using dimethyl sulfoxide (DMSO) as an additive, $\mathrm{H}_{2} \mathrm{O}$ was added to perovskite precursor to form an intermediate stabiliser with $\mathrm{Pb}^{2+}$ ion to grow high-quality perovskite films with high photovoltaic performance [22, 23]. Meanwhile, 1,8-diiodooctane additives have been proven to successfully expedite the nucleation of crystals and to modulate the kinetics of crystal growth during crystallisation, leading to more uniform perovskite morphology [5]. The use of 4-tert-butylpyridine ( $\mathrm{tBp}$ ) as an additive is not new, and numerous studies have shown that this additive can improve the PCE and photovoltaic performance of PSCs device. The tBp is frequently used in the hole-transport layer (HTL) of PSC owing to its ability to control the uniformity of HTL by avoiding the aggregation of lithium salt [26]. The chemical bond formed between $\mathrm{tBp}$ and perovskite crystals promotes the ability of the interface to become more selective for holes, thereby boosting diode rectification [27]. Similarly, the use of $\mathrm{tBp}$ in the perovskite layer improves the final product's performance. Besides, tBp also plays a significant role in perovskite crystallisation as high grain size and pinhole-free perovskite surface are reportedly achieved after tBp treatment [28].

In the current work, $\mathrm{tBp}$ was added into $\mathrm{PbI}_{2}$ precursor, replacing DMSO to enhance the photovoltaic performance of PSCs. Through this route, the addition of tBp into DMF as an additive enabled the formation of a porous layer packed $\mathrm{PbI}_{2}$ nanocrystal, and the fabrication process was conducted under ambient relative humidity $(\mathrm{RH}=40 \%-50 \%)$. We investigated the effect of MAI deposition with a time delay from 0 to $15 \mathrm{~s}$. The samples were denoted as TS-0s, DDTS5s, DDTS-10s, and DDTS-15s, which indicated the method name (i.e. delay deposition (DDTS) or TS) and the time delay. By altering the deposition technique of MAI precursor, perovskite film crystallisation seemed to significantly improve as the interfacial reaction with $\mathrm{PbI}_{2}$ proceeded. The smooth and pinhole-free perovskite film resulted in $8.3 \%$ PCE for the DDTS technique.

\section{Experimental section}

\section{Materials}

Fluorine-doped tin oxide (FTO) glass $\left(15 \Omega \mathrm{sq}^{-1}\right.$ ) was purchased from Solaronix. $\mathrm{TiO}_{2}$ blocking layer and paste (18NR-T) were purchased from Dyesol. $\mathrm{PbI}_{2}$ (99\%), MAI, lithium bis(trifluoromethanesulfonyl)imide (LiTFSI; 99\%), tBp (96\%), and 2,2',7,7'-tetrakis-( $N, N$-dip-methoxyphenylamine)-9,9'-spirobifluorene (spiroOMeTAD; 99\%) were purchased from Sigma-Aldrich. Absolute ethanol, $\mathrm{N}, \mathrm{N}$-dimethylformamide anhydrous (DMF; 99.8\%), and chlorobenzene (99\%) were purchased from R\&M Chemicals.

\section{PSC fabrication}

The FTO substrates were etched with zinc powder and $\mathrm{HCl}$ and then cleaned using ethanol, acetone, and isopropanol in an ultrasonic bath for 15 min each. The substrate was rinsed with deionised water and dried under nitrogen flow. A compact $\mathrm{TiO}_{2}$ blocking layer $\left(\right.$ bl- $\left.\mathrm{TiO}_{2}\right)$ was deposited onto the precleared FTO by spin coating $(3000 \mathrm{rpm}, 30 \mathrm{~s}) 1 \mathrm{~mL}$ of titanium isopropoxide in $1 \mathrm{~mL}$ of ethanol. A mesoporous $\mathrm{TiO}_{2}$ layer $\left(\mathrm{mp}-\mathrm{TiO}_{2}\right)$ was diluted with absolute ethanol at 1:9 ratio and coated onto $\mathrm{FTO} / \mathrm{bl}-\mathrm{TiO}_{2}$ substrate by spin coating (4000 rpm for $20 \mathrm{~s}$ ) [29]. The substrates were sintered on a hotplate at $450{ }^{\circ} \mathrm{C}$ and $30 \mathrm{~min}$ ). For the precursor solution preparation, $553 \mathrm{mg}$ of $\mathrm{PbI}_{2}$ was mixed in $1 \mathrm{~mL}$ of DMF and $100 \mu \mathrm{L}$ of tBp followed by $30 \mathrm{mg}$ of $\mathrm{CH}_{3} \mathrm{NH}_{3} \mathrm{I}$ in $1 \mathrm{~mL}$ of IPA. Both solutions were heated at $60{ }^{\circ} \mathrm{C}$ for $3 \mathrm{~h}$ under moderate stirring. Then, $70 \mu \mathrm{L}$ of $\mathrm{PbI}_{2}$ precursor solution was spin coated on the $\mathrm{mp}-\mathrm{TiO}_{2} / \mathrm{bl}-\mathrm{TiO}_{2} / \mathrm{FTO}$ substrate at $3000 \mathrm{rpm}$ for $60 \mathrm{~s}$ before heating at $70{ }^{\circ} \mathrm{C}$ for $30 \mathrm{~min}$. About $200 \mu \mathrm{L}$ of MAI precursor solution was deposited onto the substrate then spin coated at $3000 \mathrm{rpm}$ for $20 \mathrm{~s}$ before heating at $95{ }^{\circ} \mathrm{C}$ for $30 \mathrm{~min}$. For the TS method, the MAI precursor solution was dropped before spin program meanwhile 5, 10, and $15 \mathrm{~s}$ before the spin program ended for the DDTS technique. The HTL was prepared by mixing $1 \mathrm{~mL}$ of spiro-OMeTAD solution $(72.3 \mathrm{mg}$ in $1 \mathrm{~mL}$ of 
chlorobenzene), $17.5 \mu \mathrm{L}$ of Li-TFSI solution (520 mg of Li-TFSI in $1 \mathrm{~mL}$ of acetonitrile), and $28.8 \mu \mathrm{L}$ of tBp. After cooling, $50 \mu \mathrm{L}$ of spiro-OMETAD was dropped onto perovs$\mathrm{kite} / \mathrm{mp}-\mathrm{TiO}_{2} / \mathrm{bl}^{-\mathrm{TiO}_{2}} / \mathrm{FTO}$ substrate followed by spin coating at $4000 \mathrm{rpm}$ for $20 \mathrm{~s}$. Finally, the device was completed with silver (Ag) top electrode deposited by thermal evaporation. The active area of the cell was $0.07 \mathrm{~cm}^{2}$.

\section{Characterisation}

The surface morphology and cross-sectional images of the samples were observed by field-emission scanning electron microscopy (FESEM; ZEISS, Merlin Compact) and Nanosurf Easyscan2 atomic force microscopy (AFM). XRD spectra were obtained using an X-ray diffractometer model Bruker D8 advance operated at $2 \theta$ angle. Optical absorption spectra were recorded using a Lambda 35 Perkin Elmer UV-visible (UV-Vis) spectrophotometer. Solar simulated AM 1.5G sunlight was used with a solar simulator calibrated to give $100 \mathrm{~mW} / \mathrm{cm}^{2}$ using a standard Si photovoltaic cell (Daystar Meter). J-V curves were recorded with a Keithley 2400 source metre at $0.1 \mathrm{~V} / \mathrm{s}$ scan rate. Steady-state PL spectra were obtained using a fluorescence spectrometer (FLS920, Edinburgh Instruments) at an excitation wavelength of $515 \mathrm{~nm}$. All procedures were performed in ambient air without any humidity control.

\section{Result and discussion}

Figure 1a shows the device schematic of a PSC, and Fig. 1b shows a cross-sectional FESEM image of the as-prepared PSCs with layer-by-layer intermixing. Two different procedures were applied to deposit MAI and fabricate perovskite thin films, as shown in Fig. 2a. Solar cells were fabricated under $\mathrm{RH}=40 \%-50 \%$. The effects of the delay-deposition procedure of MAI on film morphology, crystal growth, and photovoltaic performance were systematically observed.

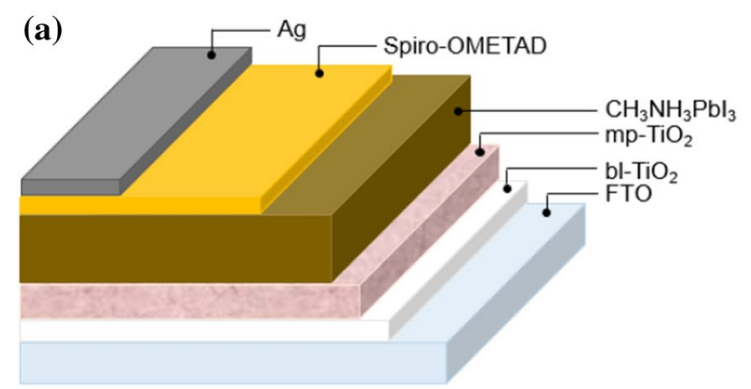

(b)

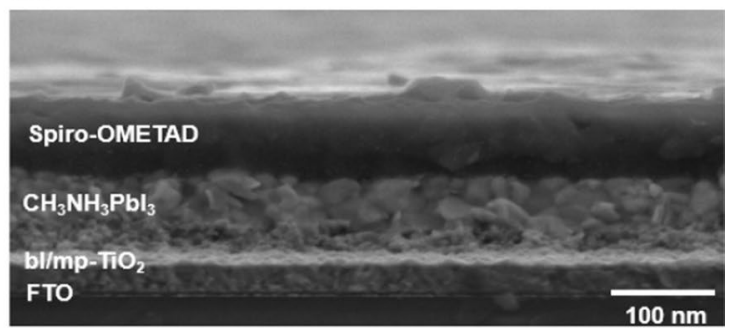

Fig. 1 a Device schematic of perovskite solar cell, and $\mathbf{b}$ cross-section FESEM of perovskite solar cells

Fig. 2 a Schematic of conventional two-step method and delay-deposition procedure of MAI for perovskite film fabrication, and $\mathbf{b}$ photographs of $\mathrm{PbI}_{2}$, TS-0s, DDTS-5s, DDTS-10s, and DDTS-15s films

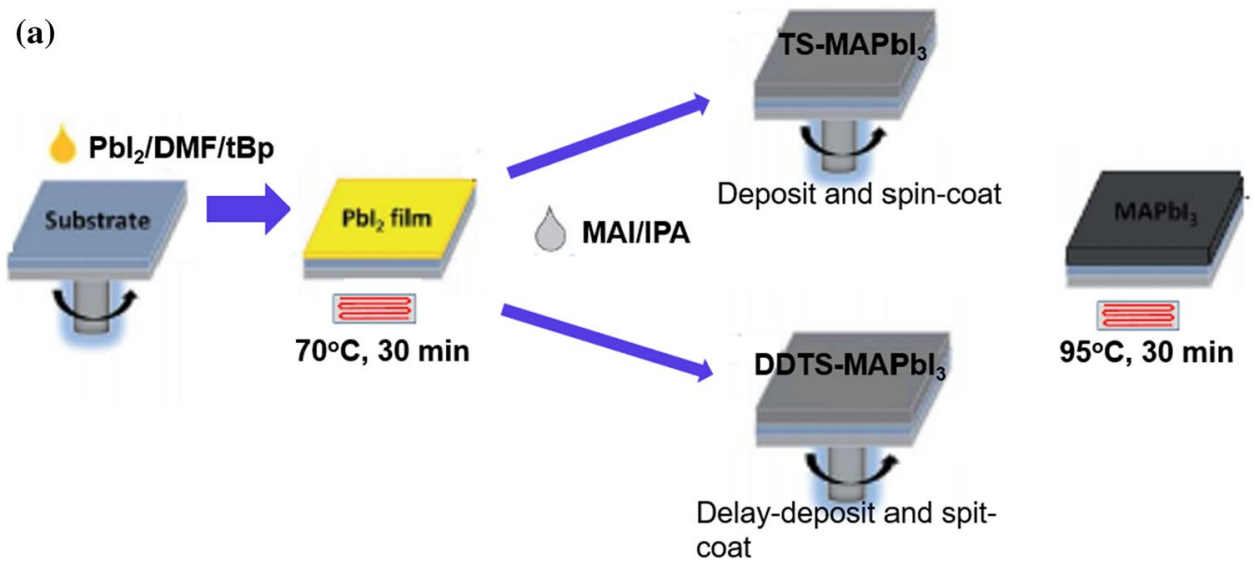

(b)

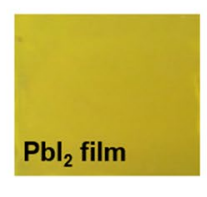

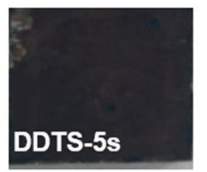

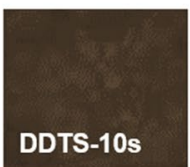

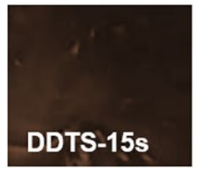

DDTS-15s 
Figure $2 \mathrm{~b}$ shows the photographs of $\mathrm{PbI}_{2}, \mathrm{TS}-0 \mathrm{~s}$, DDTS-5s, DDTS-10s, and DDTS-15s films. The as-prepared $\mathrm{PbI}_{2}$ film was pale yellow and became shiny dark yellow after $30 \mathrm{~min}$ of thermal annealing. The surface was smooth and well crystallised [30]. After TS and DDTS procedures, the perovskite films became dark brown. However, TS-0s film seemed to be dimmer, whereas DDTS-5s, DDTS-10s, and DDTS-15s films were mirror-like and dense. The TS-0s film used standard procedure to deposit MAI where the MAI precursor was deposited onto the $\mathrm{PbI}_{2}$ layer substrate and spin coated [14]. We observed the film turn into a dim dark brown, indicating the transformation of $\mathrm{PbI}_{2}$ to perovskite. This dimmer or blurred surface was caused by the light-scattering effect, which stemmed from the rough surface of the perovskite layer. The surface of DDTS-5s and DDTS-10s films looked brighter brown, and DDTS-15s showed a lighter colour and
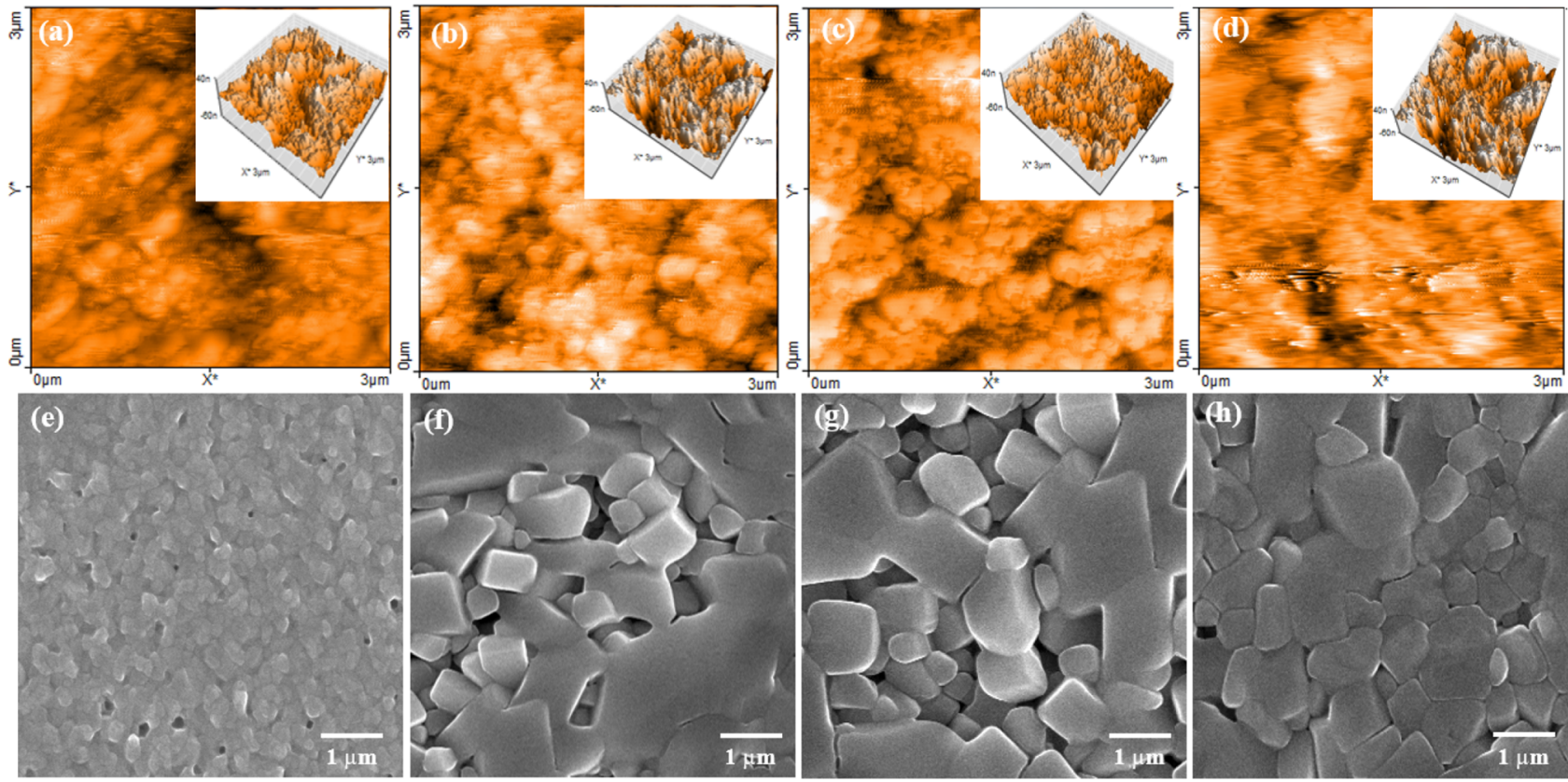

(i)

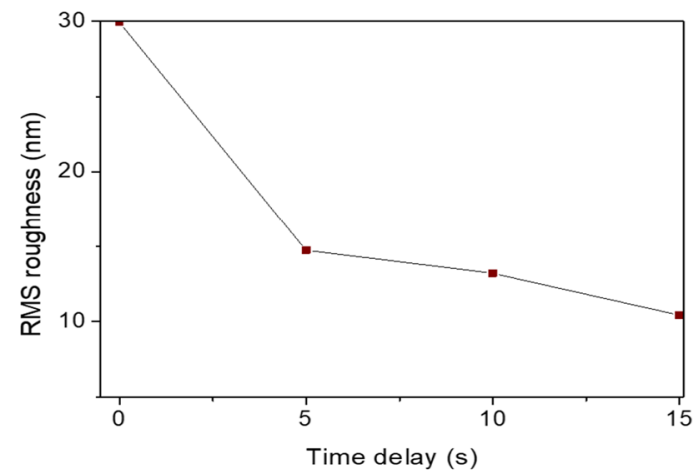

Fig. 3 a-d AFM images of TS-0s, DDTS-5s, DDTS-10s, and DDTS$15 \mathrm{~s}$, respectively. e-h FESEM surface images of TS-0s, DDTS- $5 \mathrm{~s}$, DDTS-10s, and DDTS-15s, respectively. (i) RMS roughness of per- was shiny. This finding was ascribed to the smoother film owing to the fast transformation to perovskite crystal [31].

Many reports have proven that the TS deposition method results in high quality and uniform surface morphology, but it critically depends on the handling of $\mathrm{PbI}_{2}$ film and conversion process to $\mathrm{MAPbI}_{3}$ (during MAI intercalation) [17]. Figure 3a-d shows the surface topography and 3D view of the samples through AFM. The root-mean-square (RMS) roughness values of TS-0s, DDTS-5s, DDTS-10s, and DDTS-15s were 29.92, 14.75, 13.21, and $10.42 \mathrm{~nm}$, respectively. These values eventually decreased, as shown in Fig. 3(i). The surface roughness of TS-0s showed a higher RMS value, which was correlated with the aforementioned dim and blurred surface of the sample. A smoother surface was observed when MAI precursor was deposited onto the $\mathrm{PbI}_{2}$ layer substrate $5 \mathrm{~s}$ before the spinning program ended
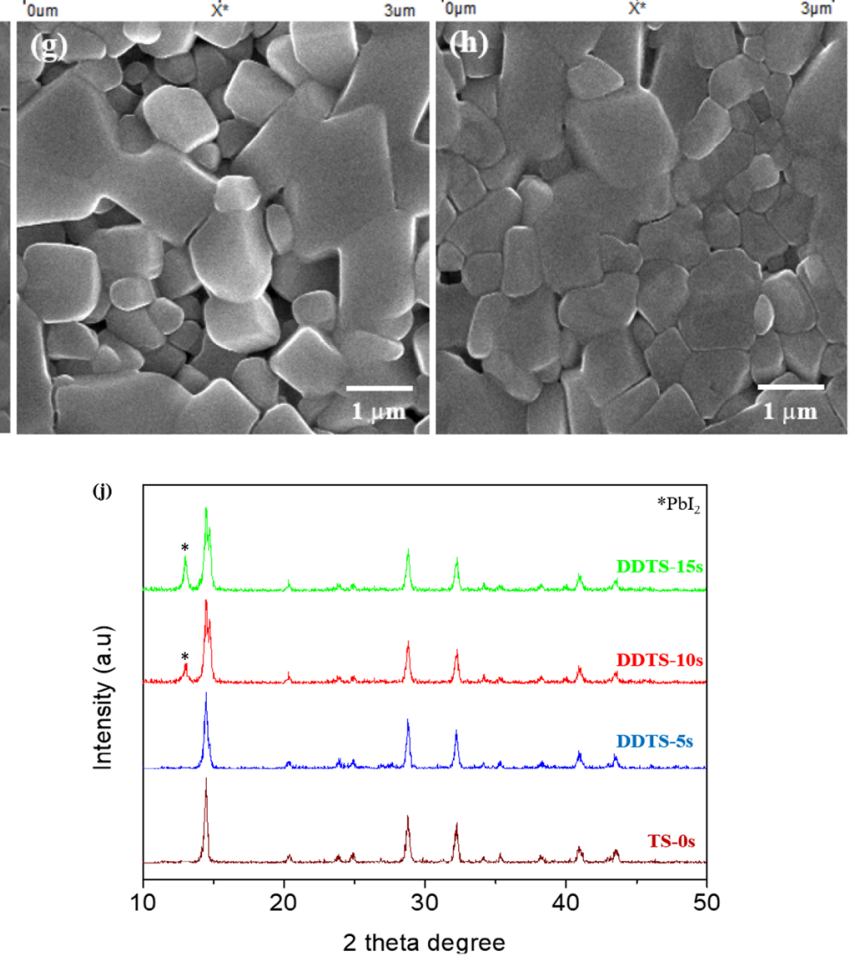

ovskite films prepared with regulated time delay (from 0 to $15 \mathrm{~s}$ ). (j) XRD patterns of perovskite films with regulated time delay (from 0 to $15 \mathrm{~s}$ ) 
(i.e. DDTS-15s). The topographical information obtained from FESEM images confirmed the morphology of the samples in Fig. 3(e-h). The compact and full-coverage perovskite film comprised packed and small grain sizes using TS methods (i.e. TS-0s), and a few pinholes appear which anticipated increasing leakage current and recombination losses in the device. Meanwhile, the grain boundaries were much clearer for DDTS samples. Pinholes and uneven grains can be observed for DDTS-5s and DDTS-10s film surfaces which can be attributed to the poorly crystallised perovskite structure. Moreover, the DDTS-15s film surface was dense and smooth.

To investigate the crystal size further, Fig. 3(j) displays the X-ray diffraction (XRD) patterns of perovskite films grown with TS and DDTS techniques. The DDTS-10s and DDTS-15s samples had a consistent peak for $\mathrm{PbI}_{2}$ at $2 \theta=12.6^{\circ}$, which corresponded to the 001 facet. However, the intensity of the diffraction peak (001) for DDTS-MAPbI was quenched, suggesting that more amount of $\mathrm{PbI}_{2}$ was successfully transformed into perovskite upon using the delay deposition of MAI. The XRD pattern of TS-0s and DDTS$5 \mathrm{~s}$ did not show the same peak, revealing that $\mathrm{PbI}_{2}$ residues cannot be converted into perovskite after MAI deposition through the standard procedure and short time delay. Thus, we found that the $15 \mathrm{~s}$ delay deposition of MAI precursor was effective and sufficient to obtain high-quality perovskite. Furthermore, tBp treatment played a significant role in the crystallisation [28, 32]. Most characteristic peaks corresponded well to $\mathrm{MAPbI}_{3}\left(\right.$ at $2 \theta=14.45^{\circ}$ and $28.68^{\circ}$ ) for all samples. The crystallinity of the samples is very important to evaluate using the full width at half-maximum (FWHM) of the characteristic diffraction peaks, and smaller FWHM of diffraction peak is known to correspond to higher crystallinity. The crystal size varied from 53.6, 48.2, 45.1, and $31.9 \mathrm{~nm}$ for TS-0s, DDTS-5s, DDTS-10s, and DDTS-15s films, respectively, in agreement with previous findings [33]. Some miscellaneous peaks were also detected, indicating that the residual $\mathrm{CH}_{3} \mathrm{NH}_{3} \mathrm{I}$ decomposed and the product was $\mathrm{I}_{2}$, as shown in the following reactions [34]:

$\mathrm{CH}_{3} \mathrm{NH}_{3} \mathrm{I}(\mathrm{aq}) \leftrightharpoons \mathrm{CH}_{3} \mathrm{NH}_{2(\mathrm{aq})}+\mathrm{HI}(\mathrm{aq})$

$4 \mathrm{HI}(\mathrm{aq})+\mathrm{O}_{2}(\mathrm{aq}) \leftrightharpoons 2 \mathrm{H}_{2} \mathrm{O}+2 \mathrm{I}$

$2 \mathrm{HI}(\mathrm{aq}) \stackrel{\text { hv }}{\Longleftrightarrow} \mathrm{H}_{2}+\mathrm{I}_{2}$

To investigate the mechanism for the better photoelectric properties of perovskite film with different times and deposition procedures of MAI, optical properties were examined. Figure 4 displays the absorption spectra of the perovskite films with time delays obtained using UV-Vis spectroscopy. TS-0s film exhibited increased absorption

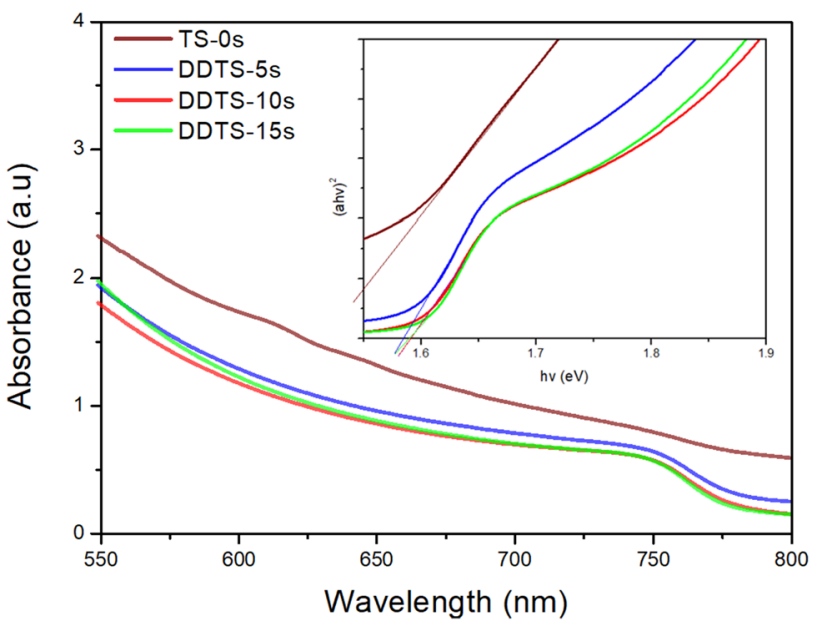

Fig. 4 Absorbance spectra of perovskite films with a regulated time delay (from 0 to $15 \mathrm{~s}$ ). The Tauc plot of each sample is plotted in the inset

intensity for wavelengths over $800 \mathrm{~nm}$, which was attributed to the light-scattering effect caused by the poor surface morphology as described earlier [14]. This finding was supported by the transmittance spectra, where lower transmittance was recorded for this sample. In other words, most photons with longer wavelengths were not transmitted properly but were scattered and reflected by the film. However, the observed light absorption in this region can be expected not to contribute to the formation of electron-hole pairs owing to the bandgap [35]. DDTS-15s film exhibited the lowest light absorption compared with DDTS-5s and DDTS-10s films. Using the Tauc analysis shown in the inset of Fig. 4, the estimated energy bandgaps of TS-0s, DDTS-5s, DDTS-10s, and DDTS-15s were 1.51, $1.57,1.58$, and $1.59 \mathrm{eV}$, respectively. The bandgap was quenched proportionally with different deposition times.

The steady-state photoluminescence (PL) spectra were obtained to further validate this phenomenon, and results are shown in Fig. 5. High-quality perovskite films are commonly related to high PL efficiency, which reduces non-radiative recombination. From the PL peak exhibited centred at $770 \mathrm{~nm}$, the peak intensity was strongly suppressed for DDTS-15s film. This finding indicated that photo-excited electrons were collected efficiently at the interface. The slower charge extraction rate of TS-0s was expected and can be defined as non-radiative charge recombination by defects or trapping holes in the film. Perovskite films were deposited onto $\mathrm{m}-\mathrm{TiO}_{2}$. Furthermore, for both cases, shifted peaks were observed owing to the usage of $\mathrm{tBp}$ in $\mathrm{PbI}_{2}$ precursor. PL intensity also decreased with prolonged time delay from 0 to $15 \mathrm{~s}$. These results confirmed the analyses of AFM and FESEM images.

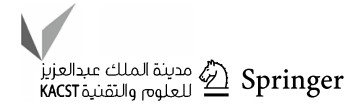




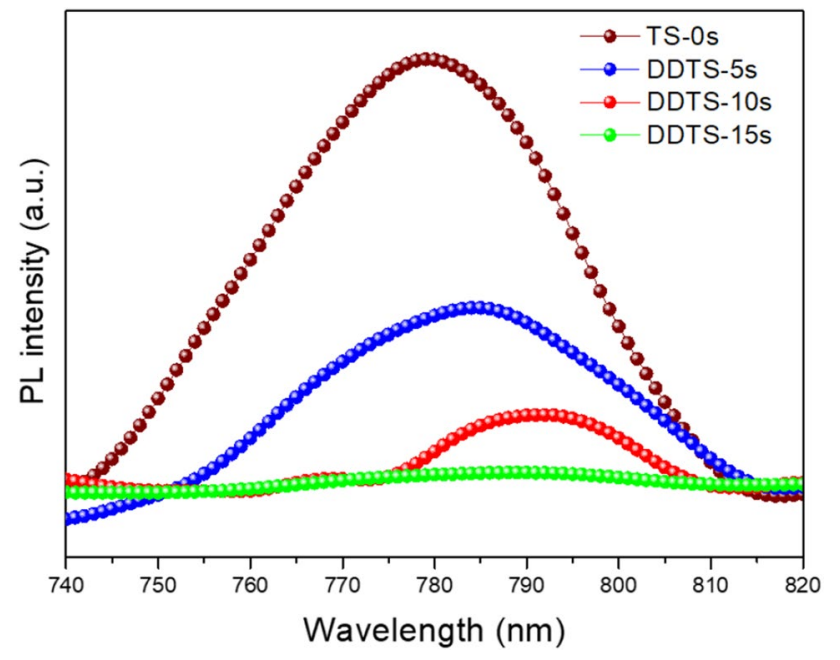

Fig. 5 Steady-state photoluminescence (PL) spectra of perovskite films with a regulated time delay (from 0 to $15 \mathrm{~s}$ )

The photovoltaic performance of the cell device was determined by the crystallinity and morphology of the resulting perovskite film. Incompatibility, defects, and pinhole surface generally lead to increased trapping holes and high recombination losses. Figure 6a shows the photocurrent density-voltage (J-V) curves of PSC device fabricated using different time delays for MAI deposition in the same batch under 1 sun illumination. Five samples comprising ten devices were used to validate the reliability of this study. They were prepared without any encapsulation in ambient air and under a $\mathrm{RH}$ of approximately $\mathrm{RH}=40 \%-50 \%$ and most likely the situation even worst during testing
$(\mathrm{RH}=70 \%-80 \%)$. Figure $6 \mathrm{~b}$ depicts the statistics of the photovoltaic parameters of the respective devices.

The external quantum efficiency (EQE) spectra of the samples were subsequently obtained, and results are shown in Fig. 7. The current produced was evaluated when the quantum efficiency was integrated over the entire electromagnetic spectrum. IPCE intensity increased from 300 to $800 \mathrm{~nm}$ with prolonged time delay from 0 to $15 \mathrm{~s}$. The current density calculated from EQE spectra was 9.37, 12.38, 13.9, and $16.96 \mathrm{~mA} / \mathrm{cm}^{2}$ for TS-0s, DDTS-5s, DDTS-10s, and DDTS-15s films, respectively, which were close to the photovoltaic performance obtained from LIV testing (Table 1). EQE can be measured based on the following formula:

$$
\begin{aligned}
\mathrm{EQE} & =\frac{\text { electron } / \mathrm{sec}}{\text { photon } / \mathrm{sec}} \\
& =\frac{\mathrm{current} /(\text { charge of } 1 \text { electron })}{(\text { total power of photons }) /(\text { energy of one photon })}
\end{aligned}
$$

In addition, the statistical photovoltaic parameters of all samples are summarised in Table 1. The average current density, $J_{\mathrm{sc}}$ increased from 9.4 to $17.2 \mathrm{~mA} / \mathrm{cm}^{2}$ with prolonged time delay from 0 to $15 \mathrm{~s}$. The average open-circuit voltage, $V_{\mathrm{oc}}$ and Fill-factor, FF slightly increased from 0.87 to $0.98 \mathrm{~V}$ and $39-50 \%$, respectively, upon changing the time delay. Eventually, the enhancement in efficiency was primarily attributed to the increase in $J_{\mathrm{sc}}$ owing to the perfect transformation of $\mathrm{PbI}_{2}$ into $\mathrm{MAPbI}_{3}$, enlargement of $\mathrm{MAPbI}_{3}$ crystallinity, light absorption of perovskite, and improved film morphologies of perovskite. The low $V_{\text {oc }}$ and FF values of TS-0s film were due to the non-uniformity of the
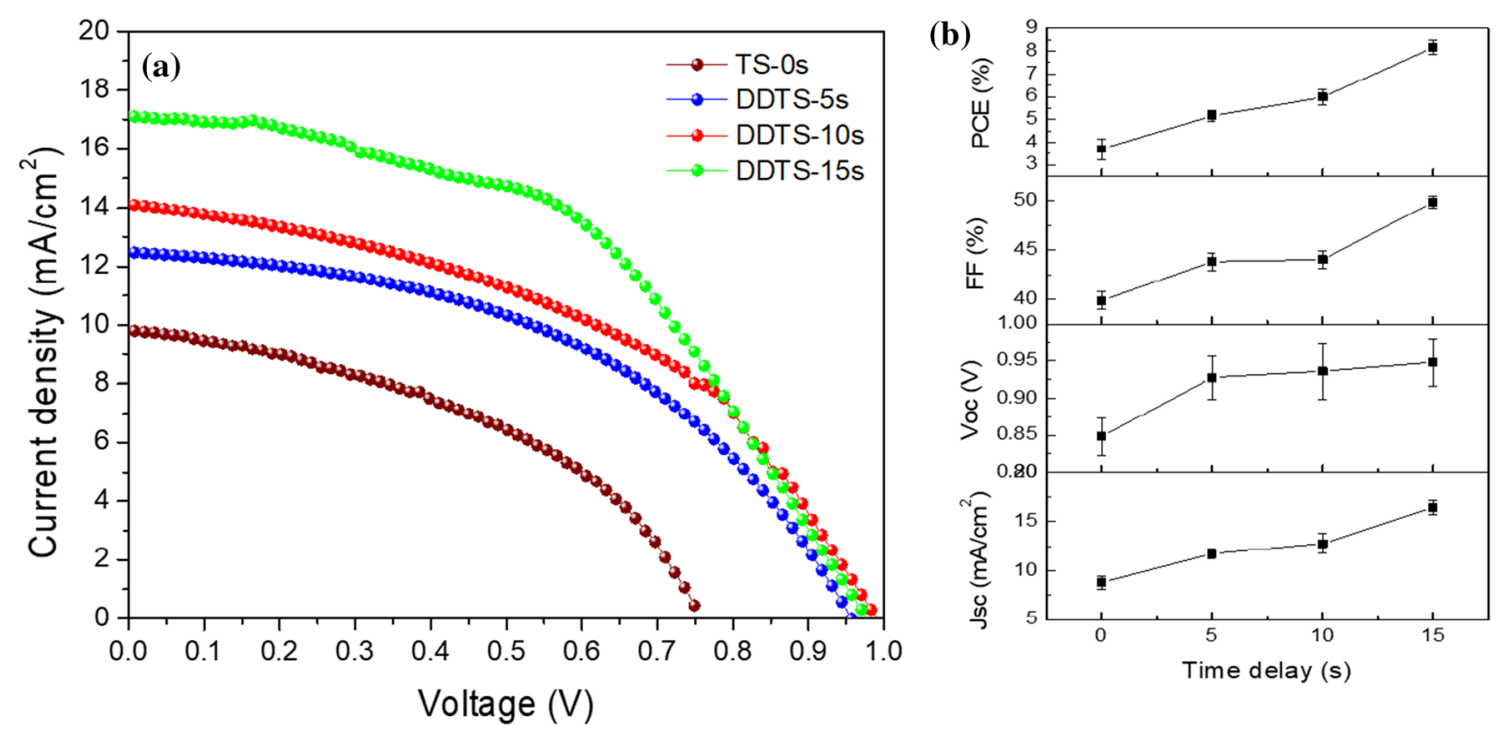

Fig. 6 a Photocurrent density-voltage (J-V) curves of PSCs using perovskite regulated time delay (from 0 to 15 s). b Average and standard deviation of photovoltaic performance parameters of at least 5 samples (10 devices) 


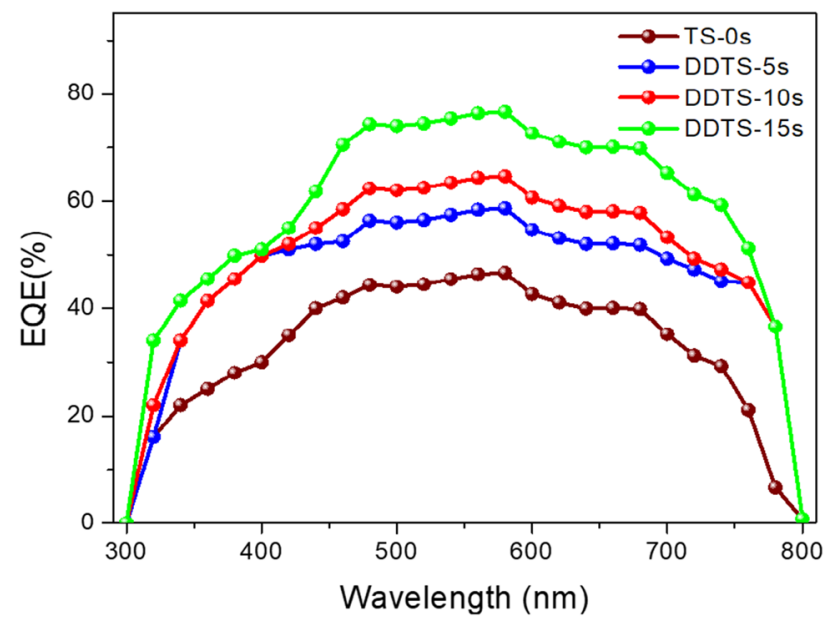

Fig. 7 External quantum efficiency (EQE) spectra using perovskite regulated time delay (from 0 to $15 \mathrm{~s}$ )

Table 1 Photovoltaic-performance parameters (short-circuit photocurrent, open-circuit photovoltage, fill factor, and power-conversion efficiency) extracted from $\mathrm{J}-\mathrm{V}$ measurements for devices under 1 sun illumination (AM $1.5 \mathrm{G}, 100 \mathrm{mV} \mathrm{cm}^{-2}$ ) for 10 devices

\begin{tabular}{lllll}
\hline Sample & $V_{\text {oc }}(\mathrm{V})$ & $J_{\mathrm{sc}}\left(\mathrm{mA} / \mathrm{cm}^{2}\right)$ & FF $(\%)$ & PCE $(\%)$ \\
\hline TS-0s & 0.870 & 9.4 & 39.00 & 3.2 \\
DDTS-5s & 0.956 & 12.7 & 44.50 & 5.4 \\
DDTS-10s & 0.978 & 14.2 & 44.76 & 6.2 \\
DDTS-15s & 0.980 & 17.2 & 50.00 & 8.3 \\
\hline
\end{tabular}

surface morphology of perovskite film, in which a few pinholes were present and the leakage current increased. Compared with the DDTS-5s, DDTS-10s, and DDTS-15s, the increased crystal size reduced the charge aggregation at the grain boundary, thereby improving the $\mathrm{FF}$ and $V_{\mathrm{oc}}$ owing to the high-quality perovskite film formation and the decreased number of shunting pathways [36]. These findings showed that time variation significantly affected the morphology and thus contributed to improving device performance.

\section{Conclusion}

A PSC device was fabricated using a TS method with the addition of $\mathrm{tBp}$ in $\mathrm{PbI}_{2}$ and DDTS of MAI from 0 to $15 \mathrm{~s}$ to understand the growth kinetics of the perovskite layer. The standard procedure of depositing MAI displayed partially complete crystallisation, which was detrimental to the overall performance. The delay-deposition route confirmed that the morphology and photovoltaic performance of the device improved. Results showed that PCE reached $8.3 \%, V_{\text {oc }}$ was $0.98 \mathrm{~V}, J_{\mathrm{sc}}$ was $17.2 \mathrm{~mA} / \mathrm{cm}^{2}$, and FF was $50 \%$. Overall, this work proved that some modifications must be considered when the $\mathrm{RH}$ was partially controlled $(\mathrm{RH}=40 \%-50 \%)$. We suggest that further investigation is needed to increase the effectiveness of this new technique with proper device encapsulation.

Acknowledgements This work was performed with the support of the Universiti Kebangsaan Malaysia Research Grant, specifically, the Dana Impak Perdana (DIP-2019-025) and Internal Grant UOW Malaysia KDU (KDURG-2017-1-004).

\section{Declarations}

Conflict of interest No conflicts of interest are declared.

Open Access This article is licensed under a Creative Commons Attribution 4.0 International License, which permits use, sharing, adaptation, distribution and reproduction in any medium or format, as long as you give appropriate credit to the original author(s) and the source, provide a link to the Creative Commons licence, and indicate if changes were made. The images or other third party material in this article are included in the article's Creative Commons licence, unless indicated otherwise in a credit line to the material. If material is not included in the article's Creative Commons licence and your intended use is not permitted by statutory regulation or exceeds the permitted use, you will need to obtain permission directly from the copyright holder. To view a copy of this licence, visit http://creativecommons.org/licenses/by/4.0/.

\section{References}

1. Tanaka, K., Takahashi, T., Ban, T., Kondo, T., Uchida, K., Miura, N.: Comparative study on the excitons in lead-halide-based perovskite-type crystals $\mathrm{CH} 3 \mathrm{NH} 3 \mathrm{PbBr} 3 \mathrm{CH} 3 \mathrm{NH} 3 \mathrm{PbI} 3$. Solid State Commun. (2003). https://doi.org/10.1016/S0038-1098(03) 00566-0

2. Stranks, S.D., Eperon, G.E., Grancini, G., Menelaou, C., Alcocer, M.J.P., Leijtens, T., Herz, L.M., Petrozza, A., Snaith, H.J.: Electron-hole diffusion lengths exceeding 1 micrometer in an organometal trihalide perovskite absorber. Science (80-. ). 342, 341-344 (2013). https://doi.org/10.1126/science.1243982

3. Eperon, G.E., Stranks, S.D., Menelaou, C., Johnston, M.B., Herz, L.M., Snaith, H.J.: Formamidinium lead trihalide: a broadly tunable perovskite for efficient planar heterojunction solar cells. Energy Environ. Sci. (2014). https://doi.org/10.1039/c3ee43822h

4. Ahn, N., Son, D.Y., Jang, I.H., Kang, S.M., Choi, M., Park, N.G.: Highly Reproducible Perovskite Solar Cells with Average Efficiency of $18.3 \%$ and Best Efficiency of $19.7 \%$ Fabricated via Lewis Base Adduct of Lead(II) Iodide. J. Am. Chem. Soc. (2015). https://doi.org/10.1021/jacs.5b04930

5. Heo, J.H., Im, S.H., Sariciftci, N.S., Smilowitz, L., Heeger, A.J., Wudl, F., Schmidt-Mende, L., Fechtenkötter, A., Müllen, K., Moons, E., Park, N.-G.: Highly reproducible, efficient hysteresisless $\mathrm{CH}_{3} \mathrm{NH}_{3} \mathrm{PbI}_{3-\mathrm{x}} \mathrm{Cl}_{\mathrm{x}}$ planar hybrid solar cells without requiring heat-treatment. Nanoscale (2016). https://doi.org/10.1039/C5NR0 $8458 \mathrm{~J}$

6. NREL: Best Research-Cell Efficiencies: Rev. 04-06-2020, (2020)

7. Liu, M.Z., Johnston, M.B., Snaith, H.J.: Efficient planar heterojunction perovskite solar cells by vapour deposition. Nature. 501, 395-+ (2013). https://doi.org/10.1038/Nature12509

8. Deng, Y., Peng, E., Shao, Y., Xiao, Z., Dong, Q., Huang, J.: Scalable fabrication of efficient organolead trihalide perovskite

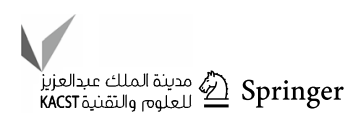


solar cells with doctor-bladed active layers. Energy Environ. Sci. (2015). https://doi.org/10.1039/c4ee03907f

9. Guarnera, S., Abate, A., Zhang, W., Foster, J.M., Richardson, G., Petrozza, A., Snaith, H.J.: Improving the long-term stability of perovskite solar cells with a porous $\mathrm{A} 12 \mathrm{O} 3$ buffer layer. J. Phys. Chem. Lett. 6, 432-437 (2015). https://doi.org/10.1021/jz502703p

10. Cheng, Y., So, F., Tsang, S.-W.: Progress in air-processed perovskite solar cells: from crystallization to photovoltaic performance. Mater. Horizons. (2019). https://doi.org/10.1039/c9mh00325h

11. Mohamad Noh, M.F., Arzaee, N.A., Nawas Mumthas, I.N., Mohamed, N.A., Mohd Nasir, S.N.F., Safaei, J., Yusoff, A.R. bin M., Nazeeruddin, M.K., Mat Teridi, M.A.: High-humidity processed perovskite solar cells. J. Mater. Chem. A. 8, 10481-10518 (2020). https://doi.org/10.1039/D0TA01178A

12. Wang, M., Feng, Y., Bian, J., Liu, H., Shi, Y.: A comparative study of one-step and two-step approaches for MAPbI3 perovskite layer and its influence on the performance of mesoscopic perovskite solar cell. Chem. Phys. Lett. (2018). https://doi.org/10.1016/j.cplett.2017.12.012

13. Zuo, C., Vak, D., Angmo, D., Ding, L., Gao, M.: One-step rollto-roll air processed high efficiency perovskite solar cells. Nano Energy (2018). https://doi.org/10.1016/j.nanoen.2018.01.037

14. Bi, D., Moon, S.J., Häggman, L., Boschloo, G., Yang, L., Johansson, E.M.J., Nazeeruddin, M.K., Grätzel, M., Hagfeldt, A.: Using a two-step deposition technique to prepare perovskite $(\mathrm{CH} 3 \mathrm{NH} 3 \mathrm{PbI} 3)$ for thin film solar cells based on $\mathrm{ZrO} 2$ and $\mathrm{TiO} 2$ mesostructures. RSC Adv. (2013). https://doi.org/10.1039/c3ra43228a

15. Burschka, J., Pellet, N., Moon, S.J., Humphry-Baker, R., Gao, P., Nazeeruddin, M.K., Grätzel, M.: Sequential deposition as a route to high-performance perovskite-sensitized solar cells. Nature (2013). https://doi.org/10.1038/nature12340

16. Huang, H., Shi, J., Zhu, L., Li, D., Luo, Y., Meng, Q.: Two-step ultrasonic spray deposition of $\mathrm{CH} 3 \mathrm{NH} 3 \mathrm{PbI} 3$ for efficient and large-area perovskite solar cell. Nano Energy (2016). https://doi. org/10.1016/j.nanoen.2016.07.026

17. Mokhtar, M.Z., Chen, M., Whittaker, E., Hamilton, B., Aristidou, N., Ramadan, S., Gholinia, A., Haque, S.A., O’Brien, P., Saunders, B.R.: CH3NH3PbI3 films prepared by combining 1- and 2-step deposition: How crystal growth conditions affect properties. Phys. Chem. Chem. Phys. (2017). https://doi.org/10.1039/ c7cp00471k

18. Li, X., Bi, D., Yi, C., Décoppet, J.-D., Luo, J., Zakeeruddin, S.M., Hagfeldt, A., Grätzel, M.: A vacuum flash-assisted solution process for high-efficiency large-area perovskite solar cells. Science (80-. ). (2016). https://doi.org/10.1126/science.aaf8060

19. Hawash, Z., Raga, S.R., Son, D.Y., Ono, L.K., Park, N.G., Qi, Y.: Interfacial modification of perovskite solar cells using an ultrathin MAI layer leads to enhanced energy level alignment, efficiencies, and reproducibility. J. Phys. Chem. Lett. (2017). https://doi.org/ 10.1021/acs.jpclett.7b01508

20. Troughton, J., Hooper, K., Watson, T.M.: Humidity resistant fabrication of $\mathrm{CH} 3 \mathrm{NH} 3 \mathrm{PbI} 3$ perovskite solar cells and modules. Nano Energy (2017). https://doi.org/10.1016/j.nanoen.2017.06.039

21. Jeon, N.J., Noh, J.H., Kim, Y.C., Yang, W.S., Ryu, S., Seok, S.: Il: Solvent engineering for high-performance inorganic-organic hybrid perovskite solar cells. Nat. Mater. (2014). https://doi.org/ 10.1038/nmat4014

22. Yang, Z., Chueh, C.C., Zuo, F., Kim, J.H., Liang, P.W., Jen, A.K.Y.: High-performance fully printable perovskite solar cells via blade-coating technique under the ambient condition. Adv. Energy Mater. (2015). https://doi.org/10.1002/aenm.201500328

23. Huang, F., Dkhissi, Y., Huang, W., Xiao, M., Benesperi, I., Rubanov, S., Zhu, Y., Lin, X., Jiang, L., Zhou, Y., Gray-Weale, A., Etheridge, J., McNeill, C.R., Caruso, R.A., Bach, U., Spiccia, L., Cheng, Y.B.: Gas-assisted preparation of lead iodide perovskite films consisting of a monolayer of single crystalline grains for high efficiency planar solar cells. Nano Energy (2014). https:// doi.org/10.1016/j.nanoen.2014.08.015

24. Adhikari, N., Dubey, A., Gaml, E.A., Vaagensmith, B., Reza, K.M., Mabrouk, S.A.A., Gu, S., Zai, J., Qian, X., Qiao, Q.: Crystallization of a perovskite film for higher performance solar cells by controlling water concentration in methyl ammonium iodide precursor solution. Nanoscale (2016). https://doi.org/10.1039/c5nr06687e

25. Cohen, B. El, Etgar, L.: Parameters that control and influence the organo-metal halide perovskite crystallization and morphology, (2016)

26. Wang, S., Sina, M., Parikh, P., Uekert, T., Shahbazian, B., Devaraj, A., Meng, Y.S.: Role of 4-tert-butylpyridine as a hole transport layer morphological controller in perovskite solar cells. Nano Lett. (2016). https://doi.org/10.1021/acs.nanolett.6b02158

27. Habisreutinger, S.N., Noel, N.K., Snaith, H.J., Nicholas, R.J.: Investigating the role of 4-tert butylpyridine in perovskite solar cells. Adv. Energy Mater. (2017). https://doi.org/10.1002/aenm. 201601079

28. Shi, Y., Wang, X., Zhang, H., Li, B., Lu, H., Ma, T., Hao, C.: Effects of 4-tert-butylpyridine on perovskite formation and performance of solution-processed perovskite solar cells. J. Mater. Chem. A. (2015). https://doi.org/10.1039/c5ta05988g

29. Ramli, N.F., Fahsyar, P.N.A., Ludin, N.A., Teridi, M.A.M., Ibrahim, M.A., Zaidi, S.H., Sepeai, S.: Compatibility between compact and mesoporous $\mathrm{TiO} 2$ layers on the optimization of photocurrent density in photoelectrochemical cells. Surfaces Interfaces. (2019). https://doi.org/10.1016/j.surfin.2019.100341

30. Yao, Z., Wang, W., Shen, H., Zhang, Y., Luo, Q., Yin, X., Dai, $\mathrm{X}$., Li, J., Lin, H.: CH3NH3PbI3 grain growth and interfacial properties in meso-structured perovskite solar cells fabricated by two-step deposition. Sci. Technol. Adv. Mater. (2017). https://doi. org/10.1080/14686996.2017.1298974

31. Deng, Y., Zheng, X., Bai, Y., Wang, Q., Zhao, J., Huang, J.: Surfactant-controlled ink drying enables high-speed deposition of perovskite films for efficient photovoltaic modules. Nat. Energy. (2018). https://doi.org/10.1038/s41560-018-0153-9

32. Wu, Y.H., Shi, X.Q., Ding, X.H., Ren, Y.K., Hayat, T., Alsaedi, A., Ding, Y., Xu, P., Dai, S.Y.: Incorporating 4-tert-butylpyridine in an antisolvent: a facile approach to obtain highly efficient and stable perovskite solar cells. ACS Appl. Mater. Interfaces. (2018). https://doi.org/10.1021/acsami.7b16912

33. Song, J., Huang, F., Chen, J., Liu, S., Cao, K., Wang, M.: High open-circuit voltage perovskite solar cell based on $\mathrm{CH} 3 \mathrm{NH} 3 \mathrm{PbBr}$ 3 light absorber using hole-conductor-layer-free structure. Chem. Eng. Trans. 62, 1147-1152 (2017). https://doi.org/10.3303/CET17 62192

34. Niu, G., Li, W., Meng, F., Wang, L., Dong, H., Qiu, Y.: Study on the stability of CH3NH3PbI3 films and the effect of post-modification by aluminum oxide in all-solid-state hybrid solar cells. J. Mater. Chem. A. (2014). https://doi.org/10.1039/c3ta13606j

35. Mohamad Noh, M.F., Arzaee, N.A., Safaei, J., Mohamed, N.A., Kim, H.P., Mohd Yusoff, A.R., Jang, J., Mat Teridi, M.A.: Eliminating oxygen vacancies in $\mathrm{SnO} 2$ films via aerosol-assisted chemical vapour deposition for perovskite solar cells and photoelectrochemical cells. J. Alloys Compd. (2019). https://doi.org/10.1016/j. jallcom.2018.09.273

36. Mohamad Noh, M.F., Arzaee, N.A., Nawas Mumthas, I.N., Fahsyar, P.N.A., Ramli, N.F., Mohamed, N.A., Mohd Nasir, S.N.F., Mohd Yusoff, A.R., Ibrahim, M.A., Mat Teridi, M.A.: Motion-dispensing as an effective strategy for preparing efficient high-humidity processed perovskite solar cells. J. Alloys Compd. (2021). https://doi.org/10.1016/j.jallcom.2020.157320

Publisher's Note Springer Nature remains neutral with regard to jurisdictional claims in published maps and institutional affiliations. 